\title{
PENGARUH KOMPETENSI MANAJERIAL DAN PELAKSANAAN SUPERVISI AKADEMIK KEPALA SEKOLAH TERHADAP MUTU PENDIDIKAN DI KUTTAB IMAM MALIK KOTA MAKASSAR
}

\author{
MUHAMMAD FAISAL R. ${ }^{1}$, ST. SYAMSUDDUHA ${ }^{2}$, DJUWAIRIAH AHMAD ${ }^{3}$ \\ 1,2,3Universitas Islam Negeri Alauddin Makassar, Indonesia \\ Email:1 1abumushab.faisal@gmail.com.2st.syamsudduha@uin-alauddin.ac.id, 3riaahmad@uin- \\ alauddin.ac.id
}

\begin{abstract}
The Effect of Managerial Competency and Implementation of School Principal Academic Supervision on the Quality of Education in Kuttab Imam Malik, Makassar City

The aims of this study were: 1) to describe the management competence of the principal at Kuttab Imam Malik Makassar; 2) To determine the implementation of the academic supervision of the Principal at Kuttab Imam Malik Makassar; 3) to determine the quality of education at Kuttab Imam Malik Makassar; 4) to examine the effect of principal management competence and academic supervision simultaneously with education quality in Kuttab Imam Malik, Makassar City. This type of research is ex post facto using a quantitative methodological approach. The results showed: (1) the management competence of school principals in Kuttab Imam Malik, Makassar City was in the moderate category, meaning that the principal had planned, organized, and controlled, but not yet maximized; (2) the competence of the regulator at the Kuttab Malik Makassar principal is also included in the medium category, meaning that the principal's program supervision plan for the supervisory supervision program has been carried out but has not been maximized; (3) and the quality of education at Kuttab Imam Malik, Makassar City is moderate, meaning that it is related to teacher professionalism, facilities and infrastructure and student learning achievement has been seen but not maximized so it needs to be improved; 4) the quality of education is strongly influenced by the managerial and academic competencies of the principal so that it becomes a reflection material for researchers and becomes a recommendation for research objects to continue to improve these competencies.
\end{abstract}

Keywords: Managerial Competence, Implementation of Academic Supervision, Quality of Education

\begin{abstract}
Abstrak: Pengaruh Kompetensi Manajerial dan Pelaksanaan Supervisi Akademik Kepala Sekolah terhadap Mutu Pendidikan di Kuttab Imam Malik Kota Makassar

Tujuan penelitian ini adalah untuk: 1) mendeskripsikan kompetensi manajemen kepala sekolah di Kuttab Imam Malik Makassar; 2) mengetahui pelaksanaan supervisi akademik kepala sekolah di Kuttab Imam Malik Makassar, 3) Mengetahui kualitas pendidikan di Kuttab Imam Malik Makassar; 4) menguji pengaruh kompetensi manajemen kepala sekolah dan supervisi akademik secara bersamaan dengan mutu pendidikan di Kuttab Imam Malik Kota
\end{abstract}


Makassar. Jenis penelitian ini adalah ex post facto dengan menggunakan pendekatan metodologi kuantitatif. Responden dalam risalah ini berjumlah 50 orang dari 61 populasi yang diperoleh dengan menggunakan simple random sampling, pengumpulan data menggunakan kuesioner yang dianalisis menggunakan statistik deskriptif dan uji inferensial dengan mengonversi F. Hasil penelitian menunjukkan bahwa: (1) kompetensi manajemen kepala sekolah di Kuttab Imam Malik Kota Makassar berada pada kategori sedang, artinya kepala sekolah sudah melakukan perencanaan, pengorganisasian, dan pengendalian, namun belum maksimal; (2) kompetensi regulator pada kepala sekolah Kuttab Malik Makassar juga berada pada kategori sedang, artinya rencana pengawasan program kepala sekolah yang dilakukan setelah memerintahkan program pengawasan telah dilakukan namun belum maksimal; (3) mutu pendidikan di Kuttab Imam Malik Kota Makassar tergolong sedang, artinya terkait dengan profesionalisme guru, sarana dan prasarana serta prestasi belajar peserta didik sudah terlihat namun belum maksimal sehingga perlu ditingkatkan; (4) Berdasarkan hasil analisis data t hitung $>t$ tabel hitung $<$ Ftabel $748.572<3,20$ menunjukkan bahwa terdapat pengaruh simultan (simultan) antara kompetensi manajerial dan kompetensi pengawas kepala sekolah terhadap mutu pendidikan. Kualitas pendidikan sangat dipengaruhi oleh kompetensi manajerial dan supervisi akademik kepala sekolah sehingga menjadi bahan refleksi bagi peneliti dan sebagai rekomendasi objek penelitian untuk terus meningkatkan kompetensi tersebut.

Kata kunci: Kompetensi Manajerial, Pelaksanaan Supervisi Akademik, Mutu Pendidikan

\section{PENDAHULUAN}

Peningkatan mutu pendidikan bukanlah hal yang sepele karena berkaitan dengan masalah teknis, perencanaan, serta efisiensi dan efektivitas penyelenggara sistem sekolah. Secara umum, kualitas dapat didefinisikan sebagai gambaran umum dan karakteristik barang dan jasa yang diharapkan atau disediakan. Dalam konteks pendidikan, pengertian mutu meliputi input, proses, dan output pendidikan (Sina, et al., 2019). Kualitas Pendidikan berkaitan dengan penilaian apakah suatu produk dapat memenuhi kriteria atau standar tertentu dengan pengukuran konkret. Mutu pendidikan dalam arti luas ditentukan oleh keseluruhan tingkat keberhasilan upaya pendidikan untuk mencapai tujuan pendidikan, baik yang berkaitan dengan mutu input, proses, maupun output pendidikan (Winarsih, 2017).

Peningkatan mutu pendidikan di lembaga pendidikan memerlukan adanya pengawasan terhadap kepala sekolah agar para pendidik dan tenaga kependidikan menjalankan tugas dan fungsinya di sekolah, salah satunya supervisi akademik (Suwartini, 2017). Supervisi akademik yang lebih difokuskan untuk membantu memantau keterampilan guru selama proses pengajaran di sekolah akan mendorong peningkatan kualitas pendidikan (Juliantoro, 2017). 
Supervisi akademik adalah bantuan profesional bagi guru, melalui siklus perencanaan yang sistematis, pengamatan yang cermat, dan umpan balik yang langsung dan objektif (Tanama et al., 2016). Dengan demikian, guru dapat menggunakan umpan balik untuk memantau pencapaiannya. Supervisi akademik merupakan bagian dari supervisi pendidikan, yaitu segala upaya berkelanjutan untuk membantu guru dan kepala sekolah mengembangkan keterampilan dan mutu pendidikan dalam mengelola pendidikan. Hal ini diharapkan dapat mendukung kualitas pendidikan dengan mengembangkan kompetensi yang dimiliki guru (Fajriana \& Aliyah, 2019). Pengawasan akademik kepala sekolah akan mencapai target jika dilakukan sesuai prosedur, artinya ada perencanaan, pelaksanaannya mengikuti aturan yang ada, dievaluasi, dan yang tidak kalah penting adalah tindak lanjut dari hasil (Diswan, 2018).

Kepala sekolah memiliki peran strategis dalam meningkatkan kualitas pendidikan di sekolah. Kepala sekolah tidak hanya bertindak sebagai pemimpin pembelajaran, tetapi lebih dari itu, kepala sekolah adalah pemimpin dari semua fungsi kepemimpinan di sekolah seperti perencanaan, pengembangan karier, koordinasi dan evaluasi (Zahro et al., 2018). Hal ini diperkuat dengan Permendiknas Nomor 13 Tahun 2007 tentang standar kepala sekolah/madrasah yang meliputi 5 kompetensi yang harus dimiliki kepala sekolah yaitu kompetensi kepribadian, kompetensi manajerial, kompetensi kewirausahaan, kompetensi pengawasan dan kompetensi sosial (Juliantoro, 2017).

Adapun nilai evaluasi kinerja Kepala Dirjen Dikti tahun 2000 adalah: 1) Mampu mengembangkan program supervisi mengajar, 2) Mampu melaksanakan program supervisi mengajar, 3) Mampu menggunakan hasil pengawasan. Oleh karena itu, subjek penelitian dalam penelitian ini adalah monitoring yang meliputi: 1) Elemen supervisi kepala sekolah untuk meningkatkan kinerja guru, 2) Strategi monitoring yang tepat untuk meningkatkan mutu pendidikan, 3) Umpan balik dan tindak lanjut Supervisi kepala sekolah untuk meningkatkan kinerja guru dengan meningkatkan mutu pendidikan akan mendorong mutu pendidikan.

Berdasarkan observasi awal yang dilakukan peneliti di Kuttab Imam Malik Kota Makassar, ditemukan bahwa lembaga pendidikan ini memiliki potensi besar untuk menjadi lembaga pendidikan yang dapat diakui kredibilitasnya dan tumbuh menjadi salah satu sekolah unggulan. Hal ini terlihat dari upaya yang dilakukan oleh kepala sekolah untuk meningkatkan mutu dan mutu pendidikan, letak sekolah yang strategis sehingga tercipta lingkungan belajar yang tertib dan nyaman, serta pengawasan yang terus menerus terhadap peserta didik oleh guru. Salah satu cara untuk mencapai ini adalah bahwa sekolah memiliki pemimpin yang dapat mengubah kinerja sekolah.

Pendidikan yang berkualitas inilah yang sangat penting di lembaga menganggap bahwa orang tua peserta didik memilih sekolah tersebut karena kualitas pendidikan 
yang dimiliki sekolah tersebut, mulai dari kualitas pendidikan di Kuttab Malik pada pengamatan awal, peneliti masih dalam tahap pengembangan sehingga masih mengalami stagnasi mulai, masalah ini menjadi masalah. Masalah utama dalam penelitian ini.

Mengacu pada temuan awal yang dilakukan selama observasi awal, peneliti menyimpulkan bahwa mandeknya mutu pendidikan disebabkan oleh permasalahan yang berkaitan dengan keterampilan yang dimiliki kepala sekolah, terutama dalam hal administrasi, supervisi, pelatihan untuk mengembangkan profesionalisme guru. Jika mengacu pada hasil penelitian terkait mutu pendidikan, peneliti menemukan banyak literatur terkait pengaruh kompetensi terhadap mutu pendidikan di sekolah.

Supervisi dan kompetensi manajerial kepala sekolah serta pengaruhnya terhadap mutu pendidikan menjadikan alasan teoretis bagi peneliti untuk menggali dan mengumumkan isu-isu terkait dengan judul yang akan diangkat, sehingga peneliti ingin membuktikan terkait peningkatan mutu pendidikan di lembaga pendidikan tidak berbeda dengan kompetensi manajerial dan supervisi akademik kepala sekolah, karena kedua unsur ini sangat penting terutama bagi perkembangan lembaga pendidikan, diantaranya lembaga pendidikan Kuttab Imam Malik Kota Makassar. Kompetensi dan supervisi akademik kepala sekolah yang dilakukan secara teoretis dapat menunjang dan meningkatkan mutu pendidikan. Berdasarkan uraian tersebut, penelitian ini dilakukan untuk mengetahui dan menguji pengaruh kompetensi manajerial dan pelaksanaan supervisi akademik kepala sekolah terhadap peningkatan mutu pendidikan di Kuttab Imam Malik Kota Makassar.

\section{METODE PENELITIAN}

Jenis penelitian yang digunakan dalam riset ini yakni penelitian kuantitatif dimana penelitian yang datanya dikumpulkan dan dianalisis berupa angka-angka. Penelitian ini terdiri dari tiga variabel, yaitu kompetensi manajerial kepala sekolah (variabel x1), supervisi akademik kepala sekolah (variabel x2), dan peningkatan mutu pendidikan (variabel y), kemudian yang akan diteliti adalah pengaruh antara variabel tersebut sehingga jenis penelitiannya termasuk penelitian kuantitatif.

Penelitian ini memungkinkan peneliti menemukan penyebab yang menghubungkan perubahan perilaku, gejala atau fenomena yang disebabkan oleh suatu peristiwa, perilaku, gejala, fenomena atau hal-hal yang menyebabkan perubahan pada variabel bebas secara keseluruhan sudah terjadi menjelaskan atau menemukan bagaimana variabel dalam penelitian yang terkait satu sama lain atau saling mempengaruhi. Permasalahan tersebut diuji untuk mengetahui penerimaan atau penolakannya berdasarkan data yang didapatkan dari lapangan.

Data yang diperoleh dari lapangan dalam bentuk skor kompetensi manajerial kepala sekolah, Supervisi Akademik Kepala Sekolah dan Mutu Pendidikan di dalam 
bentuk angka-angka yang sifatnya kuantitatif, Lokasi penelitian yang dipilih dalam penelitian ini yaitu Kuttab Imam Malik Kota Makassar.

Mengingat persoalan yang dikaji adalah hal yang terkait dengan kompetensi dan mutu yang notabenenya adalah hal yang sudah ada sehingga tidak boleh dilakukan manipulasi, sehingga peneliti memilih jenis penelitian yang dipilih adalah ex post facto dengan menggunakan pendekatan metodologi kuantitatif. Responden dalam penelitian ini berjumlah 50 orang dari 61 populasi yang diperoleh dengan menggunakan simple random sampling.

Metode-metode yang digunakan dalam mengumpulkan data pada penelitian ini yaitu angket (kuesioner) Angket atau yang sering dikenal dengan kuesioner merupakan metode pengumpulan data yang dilakukan dengan cara memberi seperangkat pertanyaan atau pernyataan tertulis kepada responden untuk dijawab, sedangkan dokumentasi adalah ditujukan untuk memperoleh data langsung dari tempat penelitian, meliputi buku-buku yang relevan, peraturanperaturan, laporan kegiatan, foto-foto, file dokumenter, data yang relevan dengan penelitian.

Teknik analisis data yang digunakan dalam penelitian ini, yaitu teknik analisis statistik deskriptif dan inferensial, dalam teknik analisis deskriptif meliputi penentuan; range, kelas interval, panjang kelas interval, mean, persentase, dan standar deviasi kemudian membuat tabel kategori, sedangkan analisis inferensial meliputi: uji normalitas, uji linearitas, uji regresi sederhana dan berganda.

\section{HASIL DAN PEMBAHASAN}

\section{Deskripsi Kompetensi Supervisi Akademik Kepala Sekolah Kuttab Imam} Malik Kota Makassar

Berikut adalah tabel hasil analisis deskriptif kompetensi manajerial kepala sekolah di Kuttab Imam Malik Kota Makassar sebagai berikut:

Tabel 1 Analisis Deskriptif Kompetensi Manajemen Kepala Sekolah Kuttab Imam Malik Kota Makassar

\begin{tabular}{cc}
\hline Statistik & Nilai Statistik \\
\hline Rata-rata & 63,46 \\
\hline Standar deviasi & 8,48 \\
\hline Rentang & 34 \\
\hline Maksimum & 76 \\
\hline Minimum & 42 \\
\hline Total skor & 3171
\end{tabular}


Penentuan kategori data kompetensi manajerial kepala sekolah di Kuttab Imam Malik Kota Makassar dalam penelitian ini menunjukkan kategorisasi berdasarkan klasifikasi mata pelajaran menjadi 3 kategori dari Azwar (2000). Tabel kategori kompetensi manajerial sebagai berikut:

Tabel 2. Kategorisasi Kompetensi Manajerial

\begin{tabular}{ccccc}
\hline Batas Kategori & Interval & Frekuensi & Persentase & Keterangan \\
\hline $\mathrm{X}<(\boldsymbol{\mu}-\mathbf{1 , 0} \boldsymbol{0})$ & $\mathrm{X}<54.98$ & 6 & $12 \%$ & Rendah \\
\hline$(\boldsymbol{\mu}-\mathbf{1 , 0 \sigma}) \leq \mathrm{X}<(\boldsymbol{\mu}+\mathbf{1 , 0 \sigma})$ & $\begin{array}{c}54.98 \leq \mathrm{X} \\
<71.94\end{array}$ & 32 & $64 \%$ & Sedang \\
& $71.94 \leq \mathrm{X}$ & 12 & $24 \%$ & Tinggi \\
\hline$(\boldsymbol{\mu}+\mathbf{1 , 0 \sigma})<\mathrm{X}$ & & $\mathbf{5 0}$ & $\mathbf{1 0 0 \%}$ & \\
\hline Jumlah & & & &
\end{tabular}

Berdasarkan tabel di atas diketahui bahwa 12\% Kompetensi Manajerial di Kuttab Imam Malik Kota Makassar termasuk dalam kategori rendah, 64\% dalam kategori sedang, dan 24\% dalam kategori tinggi. Kesimpulan analisis tersebut yakni, kompetensi manajerial kepala sekolah di Kuttab Imam Malik Kota Makassar berada pada kategori sedang. Hal ini sejalan dengan penelitian yang dilakukan oleh El-Fadaris tentang pengaruh kompetensi manajerial kepala sekolah dan motivasi belajar terhadap kinerja guru di Tarbiyatul Muallimin alIslamiyah Putri Prenduan Sumenep Madura.

\section{Deskripsi Kompetensi Supervisi Akademik Kepala Sekolah Kuttab Imam Malik Kota Makassar}

Berikut adalah tabel hasil analisis deskriptif kompetensi supervisi akademik kepala sekolah di Kuttab Imam Malik Kota Makassar sebagai berikut:

Tabel 3. Analisis Deskriptif Supervisi Akademik SD di Kuttab Imam Malik

\begin{tabular}{cc}
\multicolumn{2}{c}{ Kota Makassar } \\
\hline Statistik & Nilai Statistik \\
\hline Rata-rata & 66,28 \\
\hline Standar deviasi & 3,05 \\
\hline Rentang & 12 \\
\hline Maksimum & 73 \\
\hline Minimum & 61 \\
\hline Total skor & 3317
\end{tabular}


Penentuan kategori data Kompetensi supervisi akademik Kepala Sekolah di Kuttab Imam Malik Kota Makassar dalam penelitian ini menunjukkan kategorisasi tingkat dengan mengelompokkan mata pelajaran ke dalam 3 kategori dari (Azwar, 2000; Sitaasih, 2020).Tabel kategori kompetensi manajerial utama adalah:

Tabel 4. Kategorisasi Kompetensi Supervisi Akademik Kepala Sekolah

\begin{tabular}{ccccc}
\hline Batas Kategori & Interval & Frekuensi & Persentase & Keterangan \\
\hline $\mathbf{X}<(\boldsymbol{\mu - 1 , 0 \sigma})$ & $\mathrm{X}<63.23$ & 8 & $16 \%$ & Rendah \\
\hline$(\boldsymbol{\mu}-\mathbf{1 , 0 \sigma}) \leq \mathrm{X}<(\boldsymbol{\mu}+\mathbf{1 , 0 \sigma})$ & $63.23 \leq \mathrm{X}<69.33$ & 32 & $64 \%$ & Sedang \\
\hline$(\boldsymbol{\mu}+\mathbf{1 , 0 \sigma})<\mathrm{X}$ & $\mathrm{X} \leq 69.33$ & 10 & $20 \%$ & Tinggi \\
\hline Jumlah & & $\mathbf{5 0}$ & $\mathbf{1 0 0 \%}$ &
\end{tabular}

Berdasarkan tabel di atas diketahui bahwa 16\% Kompetensi Supervisi Akademik Kepala Sekolah di Kuttab Imam Malik Kota Makassar termasuk kategori sedang, 64\% termasuk kategori sedang, dan 20\% termasuk kategori tinggi. Kesimpulan analisis deskriptif tersebut bahwa skor kompetensi supervisi akademik kepala sekolah di Kuttab Imam Malik Kota Makassar berada pada kategori sedang. Hal ini senada dengan penelitian yang dilakukan oleh Sirajuddin Latief tentang pengaruh supervisi akademik kepala sekolah dan kompetensi pedagogik guru terhadap kinerja guru pada sikap sekolah dasar dan Kelompok Sipayung Kecamatan Kajoran Kabupaten Magelang.

\section{Deskripsi Mutu Pendidikan di Kuttab Imam Malik Kota Makassar}

Berikut adalah tabel hasil analisis deskriptif Mutu Pendidikan di Kuttab Imam Malik Kota Makassar sebagai berikut:

Tabel 5. Analisis Deskriptif Mutu Pendidikan di Kuttab Imam Malik

\begin{tabular}{cc}
\multicolumn{2}{c}{ Kota Makassar } \\
\hline Statistik & Nilai Statistik \\
\hline Rata-rata & 58,12 \\
\hline Standar deviasi & 4,24 \\
\hline Rentang & 16 \\
\hline Maksimum & 66 \\
\hline Minimum & 50 \\
\hline Total skor & 2906
\end{tabular}


Tabel 6. Kategorisasi Mutu Pendidikan di Kuttab Imam Malik Kota

\section{Makassar}

\begin{tabular}{ccccc}
\hline Batas Kategori & Interval & Frekuensi & Persentase & Keterangan \\
\hline $\mathbf{X}<(\boldsymbol{\mu - 1 , 0 \sigma )}$ & $\mathrm{X}<53.8$ & 9 & $18 \%$ & Rendah \\
\hline$(\boldsymbol{\mu - 1 , 0 \sigma )} \leq \mathrm{X}<(\boldsymbol{\mu}+\mathbf{1 , 0 \sigma})$ & $53.8 \leq \mathrm{X}<62.28$ & 31 & $62 \%$ & Sedang \\
\hline$(\boldsymbol{\mu}+\mathbf{1 , 0 \sigma})<\mathrm{X}$ & $\mathrm{X} \leq 62.28$ & 10 & $20 \%$ & Tinggi \\
\hline Jumlah & & $\mathbf{5 0}$ & $\mathbf{1 0 0 \%}$ &
\end{tabular}

Berdasarkan tabel di atas, ditemukan bahwa 18\% kualitas pendidikan di Kuttab Imam Malik Kota Makassar berada pada kategori rendah, 62\% pada kategori sedang, dan 10\% pada kategori tinggi. Kesimpulan dari tabel di atas adalah Mutu pendidikan di Kuttab Imam Malik Kota Makassar berada pada kategori sedang. Hal ini terkait juga dengan temuan penelitian Yudi Firmanysah tentang pengaruh supervisi akademik sekolah dasar dan profesionalisme guru terhadap kualitas pelayanan pendidikan.

Pengaruh Kompetensi Manajerial dan Pelaksanaan Supervisi Akademik Kepala Sekolah terhadap Mutu Pendidikan di Kuttab Imam Malik Kota Makassar

Untuk mengetahui ada tidaknya pengaruh kompetensi manajerial, kompetensi supervisi akademik terhadap mutu pendidikan, digunakan analisis regresi linier yang dapat dirumuskan sebagai berikut:

$$
\mathrm{Y}=\mathrm{a}+\mathrm{b} 1 \mathrm{X} 1+\mathrm{b} 2 \mathrm{X} 2 \text {. }
$$

Tabel 7. Uji Regresi Linier Berganda

\begin{tabular}{|l|c|c|c|c|}
\hline \multicolumn{1}{|c|}{ Variabel } & $\boldsymbol{\alpha}$ (constan) & Koefisien regresi & F hitung & F tabel \\
\hline Kompetensi manajerial & & 0,216 & \multirow{2}{*}{748,52} & \\
\hline Kompetensi supervisi akademik & $-5,188$ & 0,747 & & \\
\hline
\end{tabular}

Berdasarkan tabel tersebut dapat diperoleh hasil persamaan regresi linier sebagai berikut:

$$
\begin{aligned}
& \mathrm{Y}=\mathrm{a}+\mathrm{b} 1 \mathrm{X} 1+\mathrm{b} 2 \mathrm{X} 2 \\
& \mathrm{Y}=-5,188+0,216 \mathrm{X} 1+0,747 \mathrm{X} 2
\end{aligned}
$$

Model menunjukkan bahwa konstanta $(\alpha)$ adalah 5,188 yang berarti kompetensi manajerial dan supervisi akademik bernilai 0 maka mutu pendidikan negatif, yaitu 6,384. Nilai koefisien regresi untuk variabel kompetensi manajerial positif, yaitu sebesar 0,216, artinya untuk setiap peningkatan satu satuan mutu kompetensi manajerial maka mutu pendidikan akan meningkat menjadi 0,216. Sebaliknya jika terjadi penurunan satu satuan kualitas kompetensi manajerial seorang siswa, maka kualitas pendidikan akan meningkat. Pendidikan akan turun 
0,216. Apabila nilai koefisien regresi kompetensi supervisi akademik bernilai positif yaitu 0,747 yang berarti bahwa untuk peningkatan satu satuan mutu kompetensi supervisi akademik maka peningkatan mutu pendidikan diikuti oleh $0, b_{1} b_{2}$

Tabel 8. Hasil Hipotesis dan Uji - Y dengan SPSS $24 X_{1} X_{2}$

\begin{tabular}{cccccc}
\hline $\mathbf{R}$ & $\mathbf{R 2}$ & $\boldsymbol{f}$ perhitungan & $\boldsymbol{f}$ meja & Sig & Kesimpulan \\
\hline $\mathbf{0 , 9 8 5}$ & 0,970 & 748.572 & 3.20 & 0,000 & $\begin{array}{c}\text { Korelasi Positif } \\
\text { Signifikan }\end{array}$
\end{tabular}

Dari tabel Model Summary, nilai $=0,970$, artinya variabel independen (X1) Kompetensi manajerial, (X2) kompetensi supervisi akademik dapat memprediksi jumlah variabel tergantung kualitas pendidikan sebesar 97\%, sisanya 3\% dijelaskan oleh faktor lain Output di atas juga menjelaskan bahwa $\mathrm{R}$ nilainya adalah 0,985. Dari hasil analisis tersebut maka disimpulkan bahwa terdapat hubungan yang kuat antara kompetensi manajerial dan kompetensi supervisi akademik terhadap mutu pendidikan. Hasil pada tabel Anova memperoleh nilai sebesar 748.572, dengan begitu maka dapat disimpulkan bahwa Kompetensi manajerial serta kompetensi supervisi akademik kepala sekolah berpengaruh secara simultan (simultan) terhadap kualitas pendidikan.

Dari hasil analisis data dapat dikatakan bahwa kompetensi kepala sekolah Kuttab Imam Malik termasuk kategori sedang, sangat kuat dan signifikan terhadap mutu pendidikan. Susanto (2018) menekankan bahwa kepala sekolah sebagai pengelola hendaknya mampu melaksanakan tanggung jawabnya dalam upaya peningkatan dan pengembangan keprofesian guru, dalam hal ini kepala sekolah harus dapat memfasilitasi dan memberikan kesempatan yang seluas-luasnya kepada guru untuk melakukan kegiatan pengembangan keprofesian dengan berbagai pendidikan dan pelatihan, baik kegiatan pelatihan dilakukan di sekolah, KKG, in-house training, diskusi profesional dan sebagainya. Analisis dilakukan pada dimensi program pengawasan yang terdiri dari tiga indikator, yaitu: kepala sekolah memfasilitasi rencana tindak lanjut, kepala sekolah melakukan pembinaan dan pengembangan, dan penggunaan data hasil pemantauan sebagai bahan untuk meningkatkan kinerja. dari pelaksanaan program.

Peran kepala sekolah sebagai supervisor yakni rutin melakukan kunjungan kelas untuk mengamati dan melihat guru menggunakan metode, media yang digunakan dan keterlibatan peserta didik dalam pembelajaran. Dari hasil observasi tersebut dapat diketahui kekurangan serta kelebihan guru dalam melakukan pengajaran, tingkat pengetahuan keterampilan guru terhadap materi tersebut, kemudian dicarikan solusi, pembinaan dan tindak lanjut. apakah guru dapat memperbaiki kekurangan yang ada dalam mempertahankan keunggulan dalam melaksanakan pembelajaran (Rusmawati, 2013). 
Hasil penelitian ini membuktikan bahwa dua teori yang dikemukakan mengenai kompetensi manajemen serta kompetensi supervisi akademik kepala sekolah berpengaruh terhadap kualitas pendidikan di Kuttab Imam Malik. Hal ini didukung oleh besarnya pengaruh kompetensi manajerial dan supervisi akademik kepala sekolah terhadap mutu pendidikan di Kuttab Imam Malik Kota Makassar, meskipun hasil kompetensi manajerial dan supervisi akademik kepala sekolah berada pada kategori sedang, hal ini dapat memperkuat pemahaman tentang pentingnya peran kompetensi kepala sekolah terhadap pengaruh kualitas pendidikan khususnya yang terjadi di Kuttab Imam Malik Kota Makassar.

Konteks penelitian ini juga telah ditelaah dalam penelitian yang dilakukan oleh Astuti \& Danial (2019) terkait pentingnya kepala madrasah yang terus menerus mengupayakan kedisiplinan agar dapat dipertahankan dan dimajukan melalui kesadaran warga madrasah akan tanggung jawabnya dalam menjalankan tugasnya. Madrasah. Oleh karena itu, peran kepala sekolah pada umumnya meliputi kompetensi yang dimiliki yang sangat penting bagi perkembangan sekolah (Danial \& Damopolii, 2019).

Kualitas pendidikan sangat dipengaruhi oleh kompetensi manajerial dan supervisi akademik kepala sekolah sehingga hal ini menjadi bahan refleksi bagi peneliti dan rekomendasi agar objek penelitian terus berupaya meningkatkan kompetensi tersebut dalam upaya peningkatan mutu pendidikan di Kuttab Imam Malik Kuta Makassar.

\section{KESIMPULAN}

Berdasarkan hasil penelitian dan pembahasan yang dilakukan peneliti, kesimpulan dari penelitian ini adalah: 1) Kompetensi manajemen kepala sekolah di Kuttab Imam Malik Kota Makassar berada pada kategori sedang sebesar 64\%, artinya kepala sekolah menjalankan fungsi manajerial dengan baik, namun tidak secara optimal; 2) Kompetensi supervisi akademik kepala sekolah Kuttab Imam Malik Makassar berada pada kategori sedang sebesar 64\%, artinya kepala sekolah menjalankan fungsi supervisi akademik dengan baik, namun belum maksimal; 3) Kualitas pendidikan di Kuttab Imam Malik Kota Makassar termasuk dalam kategori sedang dengan persentase 62\%. 4) Kompetensi manajerial dan kompetensi supervisi akademik berpengaruh secara simultan (simultan) terhadap kualitas pendidikan kompetensi manajerial dan kompetensi supervisi akademik dapat memprediksi jumlah variabel terikat mutu pendidikan hingga 97\%, yang masih 3\% dijelaskan oleh faktor lain. 


\section{DAFTAR PUSTAKA}

Astuti, A., \& Danial, D. (2019). Kepemimpinan Kepala Madrasah dalam Membangun Budaya Madrasah Yang Kondusif di Madrasah Aliyah Negeri. El-Idare: Jurnal Manajemen Pendidikan Islam, 5(1), 31-45.

Azwar, S. (2000). Asumsi dalam Inferensi Statistik. Buletin Psikologi, 9 (1)., 9(1).

Danial, D., \& Damopolii, M. (2019). Hubungan antara Budaya Madrasah dengan Motivasi Kerja Guru di MTs se-Kecamatan Sinjai Barat. Lentera Pendidikan, 22(1), 141-156. https://doi.org/https://doi.org/10.24252/lp.2019v22n1i12

Diswan. (2018). Peran Kepemimpinan Kepala Sekolah dalam Meningkatkan Kualitas Pembelajaran di Yayasan Sekolah Menengah Al-Hidayah Medan Tembung (Disertasi Doktor Universitas Islam Negeri Sumatera Utara). Disertasi.

Fajriana, A. W., \& Aliyah, M. A. (2019). Tantangan Guru Meningkatkan Kualitas Pendidikan Agama Islam di Era Milenial. Nazhruna: Jurnal Pendidikan Islam, 2(2), 246-265.

Juliantoro, M. (2017). Peran Kepala Sekolah dalam Peningkatan Mutu Pendidikan. Al-Hikmah: Jurnal Pendidikan Dan Syariah, 5(2), 24-38.

Rusmawati, V. (2013). Peran Kepemimpinan Kepala Sekolah dalam Upaya Meningkatkan Disiplin Kerja Guru pada SDN 018 Balikpapan. Jurnal Administrasi Negara, 1(2), 1-19.

Sina, R., Fatmawati, \& Mahsyar, A. (2019). Implementasi Sistem Informasi Manajemen Pendidikan (Emis) pada Lembaga Pendidikan Agama dan Pesantren di Kantor Kementerian Agama Makassar. JPPM: Jurnal Kebijakan Dan Manajemen Publik, 1(1), 38-48.

Sitaasih, D. K. (2020). Supervisi Akademik untuk Meningkatkan Kompetensi Guru Selama Proses Pembelajaran di Sekolah Dasar. Jurnal Ilmiah Sekolah Dasar, $4(2), 241-247$.

Susanto, A. (2018). Bimbingan dan konseling di Sekolah: Konsep, teori, dan aplikasinya. Jakarta: Kencana.

Suwartini, E. A. (2017). Supervisi Akademik Kepala Sekolah, Profesionalisme Guru dan Mutu Pendidikan. Jurnal Administrasi Pendidikan, 24(2).

Tanama, Y. J., Supriyanto, A., \& Burhanuddin. (2016). Pelaksanaan Supervisi Klinis untuk Meningkatkan Profesionalisme Guru. Jurnal Pendidikan: Teori, Penelitian, Dan Pengembangan, 11(1), 2231-2235.

Winarsih, S. (2017). Kebijakan dan Implementasi Manajemen Perguruan Tinggi untuk Meningkatkan Mutu Pendidikan. Sarjana: Jurnal Pendidikan Dan Masyarakat, 15(1), 51-66.

Zahro, A. M., Sobri, A. Y., \& Nurabadi, A. (2018). Perubahan kepemimpinan kepala sekolah untuk meningkatkan kualitas pendidikan Manajemen Pendidikan. JAMP: Jurnal Administrasi Dan, 3(1), 358-363. 